\title{
Poly(ethylene terephthalate)-carbon nanofiber nano composite for fiber spinning; properties and combustion behavior
}

\author{
Jenny Alongi, ${ }^{1 *}$ Alberto Frache ${ }^{2}$ \\ ${ }^{1 *}$ Viale Teresa Michel 5, 15121 Alessandria, Italia; tel/fax: +39 0131 229337/+39 \\ 0131 229399; e-mail: jenny.alongi@polito.it; alberto.frache@polito.it \\ ${ }^{2}$ Dipartimento di Scienza dei Materiali e Ingegneria Chimica, Politecnico di Torino, \\ Corso Duca degli Abruzzi 24, 10129 Torino, Italy.
}

(Received: 15 March, 2010; published: 01 August, 2010)

\begin{abstract}
Carbon nanofiber (CNF)-polyethylene terephthalate (PET) blends were previously prepared by melt blending and, subsequently, melt spun in order to obtain nanostructured fibers characterized by high flame retardant properties and resistance to the combustion. The morphological analysis showed that CNFs are homogeneously distributed and finely dispersed within PET matrix. The mechanical properties in tensile testing of the fibers change in the presence of CNFs: the elongation at break increases, whereas the tenacity and the tensile strength decrease. The combustion tests by cone calorimetry reveal a relevant decrease of heat release rate, total heat evolved and total smokes released by the nanocomposites as compared to neat PET.

Keywords: carbon nanofibers; CNF; PET; nanocomposites;
\end{abstract}

\section{Introduction}

In the last twenty years, there has been a high level of interest in using filler particles having at least one dimension of nano-scale size (nanofiller) in order to reach substantial improvements with low filler loading $(<5 \mathrm{wt} . \%)$ [1-4]. One of the most promising applications involves the improvement in flame retardancy properties of polymers added with nanofillers. The possibility to reduce flammability of numerous polymers using nanoclays have been shown by many authors and several mechanisms are proposed [5-17]. Indeed, nanocomposite systems are a new attractive alternative to conventional commercial flame retardants. Nowadays, the most common approach to nanocomposite fire retardants is based on the use of layered silicates characterized by a large aspect ratio. Carbon nanotubes and carbon nanofibers are suitable candidate as flame retardant: Kashiwagi and coworkers [13, 14] demonstrated that multi-walled carbon nanotubes can be used for reducing the flammability properties of polypropylene, and that it is possible also to use single walled carbon nanotubes for poly(methyl methacrylate) for the same purpose [15]. These fillers are also used as reinforcement. The in situ formation of a continuous surface protective charred layer embedding carbon nanotubes is playing a protective and remarkable role for the relevant reduction of total heat released as well as heat release rate during the combustion of carbon nanotubes polymer nanocomposite material [16-18]. Despite similarities between carbon nanofibers (CNFs) and carbon nanotubes, there are no published studies on CNF use for preparing polymer nanocomposites for the reduction of flammability. Ma et al. [19] reported on fibers spun from polyester/carbon nanofiber composites. In this study, different grades of 
CNFs have been melt blended with poly(ethylene terephthalate) and then spun into fibers; the authors compared compounding behavior using either twin-screw extruder, or two-roll mill, or high shear mixer, in order to establish the dispersion level of carbon nanofibers and the related mechanical properties. They observe that the tensile strength and modulus were not significantly increased by the addition of nanofibers, whereas compressive strength and torsional moduli of composite fibers were considerably higher than for neat PET fibers.

In this work, different grades of CNFs have been melt compounded with poly (ethylene terephthalate) and then spun into fibers. Morphology, thermal stability, mechanical and flame retardancy properties have been investigated.

\section{Results and discussion}

\section{PET-CNF nanocomposites}

\section{-Morphology}

Carbon nanofibers, CNFPS and CNFLHT, are cylindrical nanostructures of graphene arranged layers, characterized by a complicate bundling due to their length (Figure 1). Apparently, relevant differences in terms of purity grade are not visible.
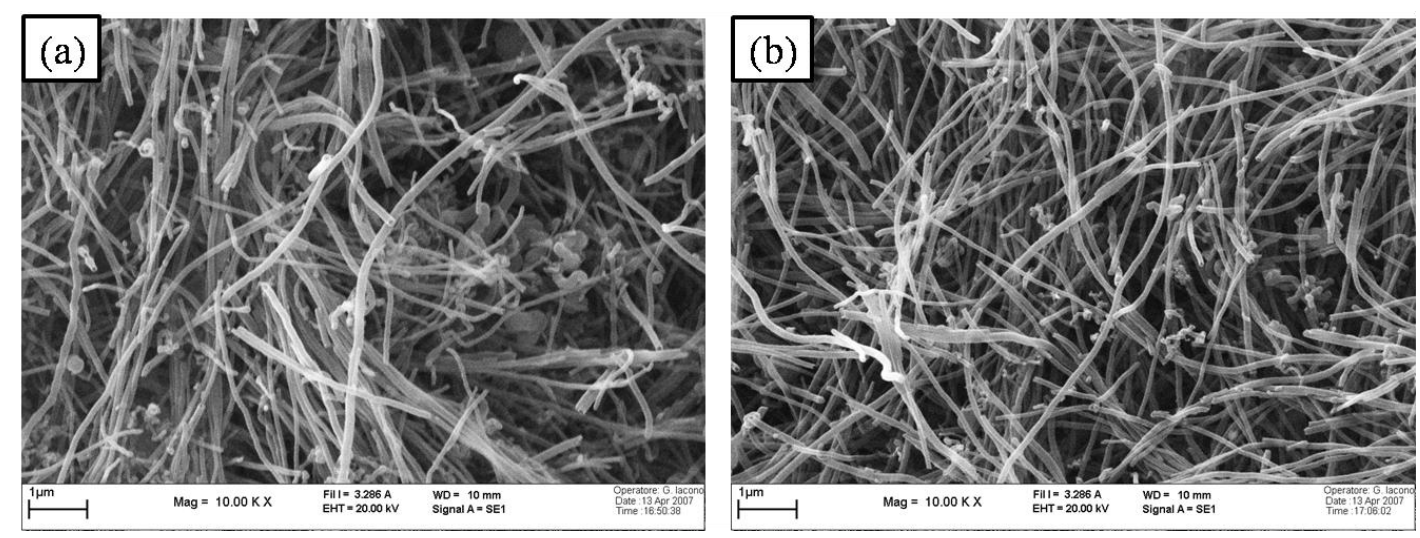

Fig. 1. SEM micrographs of CNFPS (a) and CNFLHT (b) carbon nanofibers.
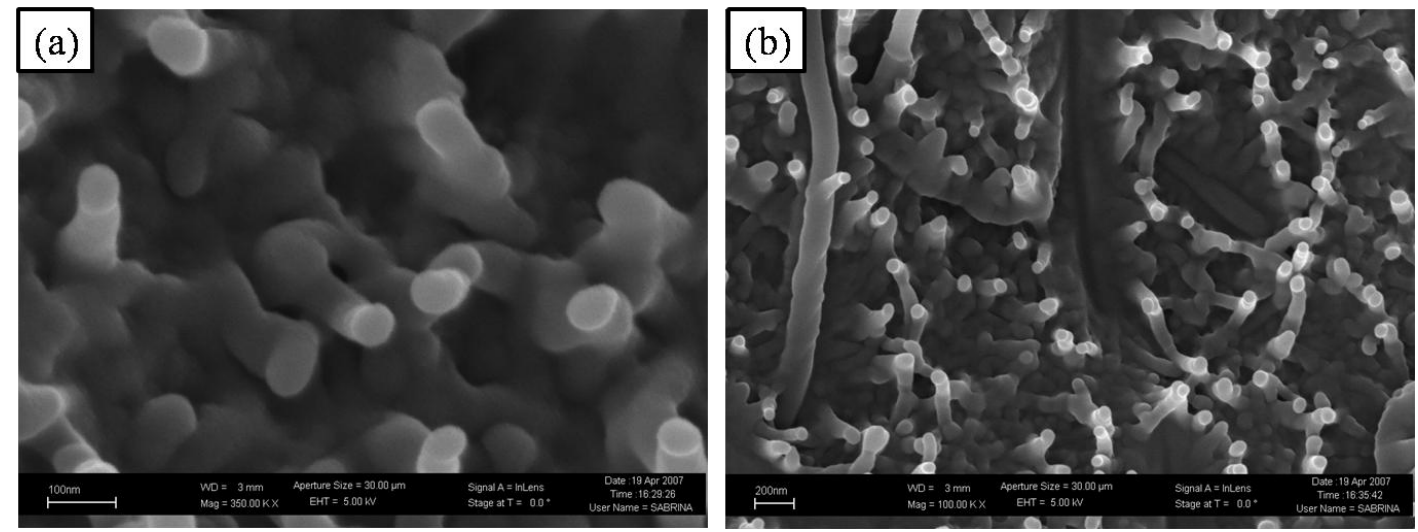

Fig. 2. FESEM micrographs at different magnifications of CNFLHT carbon nanofibers.

From the statistical investigation of FESEM images of the type shown in Figure 2, it has been found that in the case of CNFPS (Figure 3a), the major part of fibers have a 
diameter in the range $40-80 \mathrm{~nm}$ (ca.80\%), whereas in the case of CNFLHT $80 \%$ fibers fall in the range 40-100 $\mathrm{nm}$ (Figure 3b).
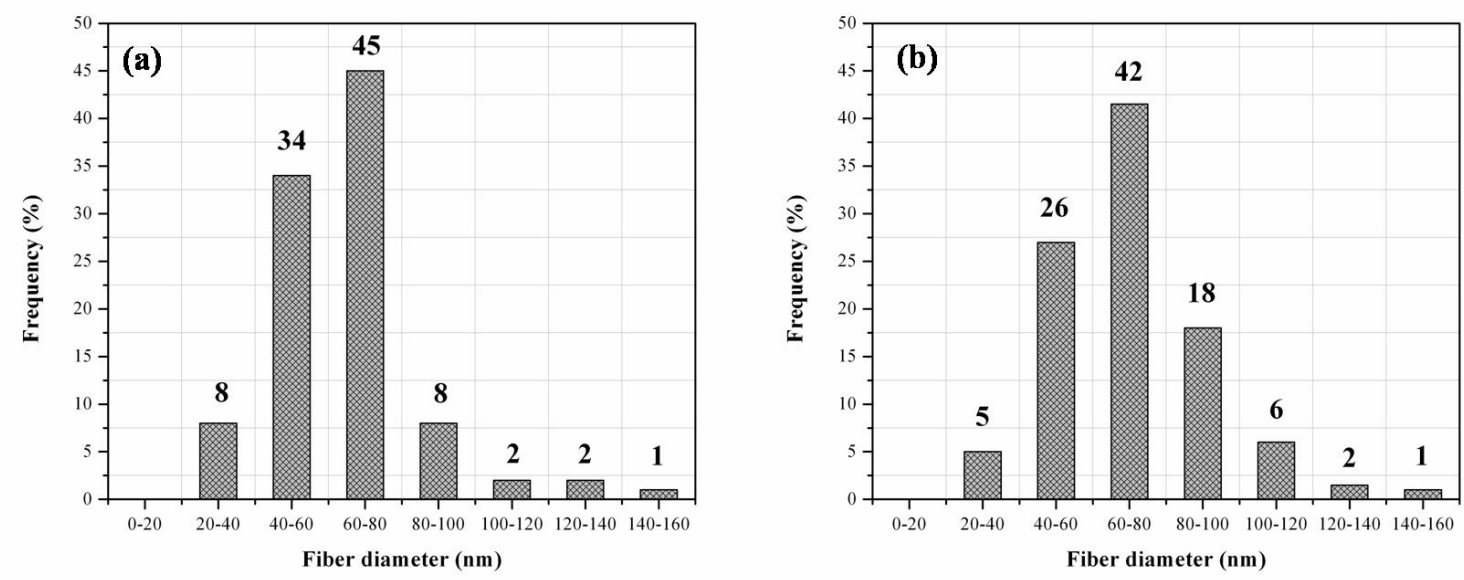

Fig. 3. Statistical data of CNFPS (a) and CNFLHT (b) carbon nanofibers.

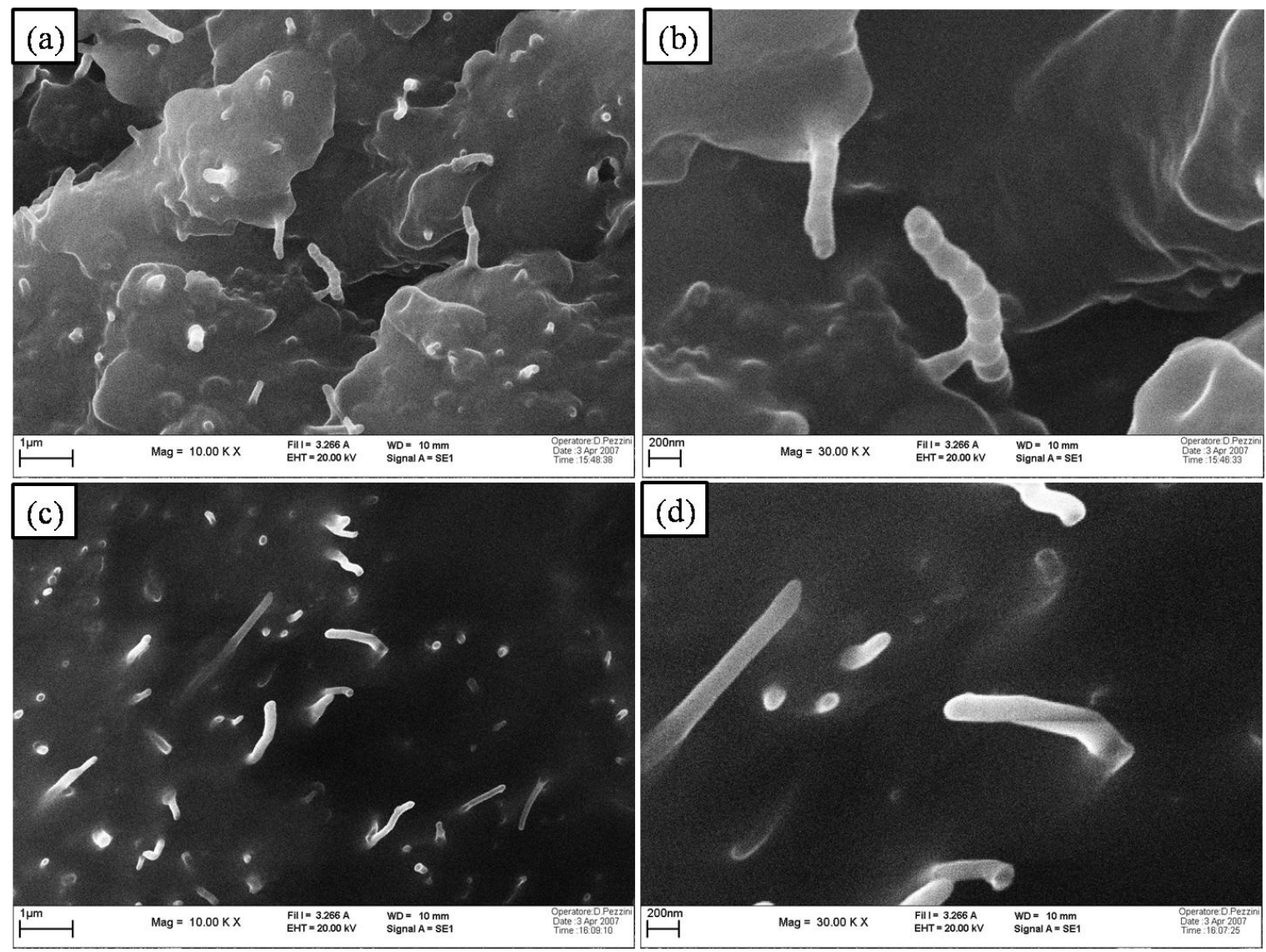

Fig. 4. SEM micrographs of PET-CNFPS (a, b) and CNFLHT (c, d) nanocomposites.

When these fibers are introduced in the polymer matrix, a homogeneous and uniform distribution, as well as a high level dispersion are evident, as shown in Figure 4. 


\section{-Thermal stability}

Thermal stability of PET changes in presence of CNFs, as shown in Table 1. In nitrogen, the CNFs anticipate the weight loss, whereas in air they delay the degradation. Indeed, the $T_{\text {onset }}$ at $5 \%$ in the nanocomposites is lower in nitrogen and higher in air, respectively, as compared to PET; whereas, in either atmosphere, the $T_{\max }$ decreases for the presence of both the carbon nanofibers. In nitrogen volatilization occurs in a single step whereas a carbonization phenomenon is present in air with formation of a char residue ( $\left.T_{\max 1}\right)$ which is oxidized at higher temperature $\left(T_{\max 2}\right)$.

Tab. 1. TGA data of PET-CNF nanocomposites.

\begin{tabular}{cccccc}
\hline Formulation & $\begin{array}{c}\mathrm{T}_{\text {onset 5\% }} \\
{\left[{ }^{\circ} \mathrm{C}\right]}\end{array}$ & $\begin{array}{c}\mathrm{T}_{\max 1} \\
{\left[{ }^{\circ} \mathrm{C}\right]}\end{array}$ & $\begin{array}{c}\mathrm{T}_{\max 2} \\
{\left[{ }^{\circ} \mathrm{C}\right]}\end{array}$ & $\begin{array}{c}\text { Residue at } 800{ }^{\circ} \mathrm{C} \\
{[\%]}\end{array}$ \\
\hline Nitrogen & & & & & \\
\hline & PET & 419 & 461 & - & 9.5 \\
& PET-CNFPS & 411 & 455 & - & 15.8 \\
& PET-CNFLHT & 415 & 456 & - & 18.9 \\
\hline Air & & & & & \\
\hline & PET & 402 & 457 & 577 & 1.0 \\
& PET-CNFPS & 410 & 457 & 568 & 0.4 \\
& PET-CNFLHT & 404 & 457 & 555 & 0.6 \\
\hline
\end{tabular}

DSC data of Table 2 and in Figure $5 a$ show that the crystallization temperature $\left(T_{c}\right)$ increases in the presence of CNFs acting as nucleating agents. It is also seen that the nanocomposites show a slightly lower melting temperature $\left(T_{m}\right)$ as compared to neat PET (Figure $5 b)$. Finally, the crystallinity $\left(X_{c}\right)$ of PET is increased from 30 up to $34 \%$ for both types of CNFs (Table 2).

Tab. 2. DSC data of PET-CNF nanocomposites.

\begin{tabular}{ccccc}
\hline Formulation & $\mathrm{T}_{\mathrm{c}}$ & $\Delta$ & $\mathrm{T}_{\mathrm{m}}$ & $\mathrm{X}_{\mathrm{c}}$ \\
& {$\left[{ }^{\circ} \mathrm{C}\right]$} & {$\left[{ }^{\circ} \mathrm{C}\right]$} & {$\left[{ }^{\circ} \mathrm{C}\right]$} & {$[\%]$} \\
\hline PET & 200 & - & 255 & 30 \\
PET-CNFPS & 213 & +13 & 249 & 34 \\
PET-CNFLHT & 215 & +15 & 251 & 34 \\
\hline
\end{tabular}

\section{-Combustion behavior}

The cone calorimetry data are shown in Table 3 and represented graphically in Figure 6. Regarding TTI, both formulations give a decrease of the ignition time (22\%). The pkHRR decreases from 523 to 340 and $318 \mathrm{~kW} / \mathrm{m}^{2}$ for PET-CNFPS and PETCNFLHT (35 and 39\%, respectively). An average 15\% reduction in smoke production (TSR and SEA) is observed for CNFLHT based nanocomposite whereas it is negligible in the case of CNFPS.

The flammability behavior of the samples prepared is completed by LOI test: LOI value increases from 21 up to 23 for both formulations $(+10 \%)$ (Table 3 ). 
(a)

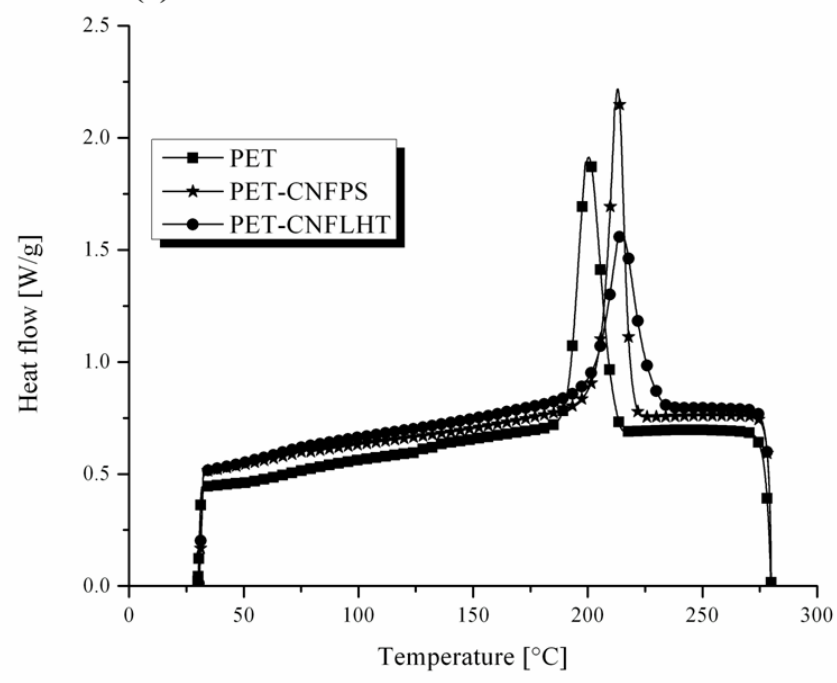

(b)

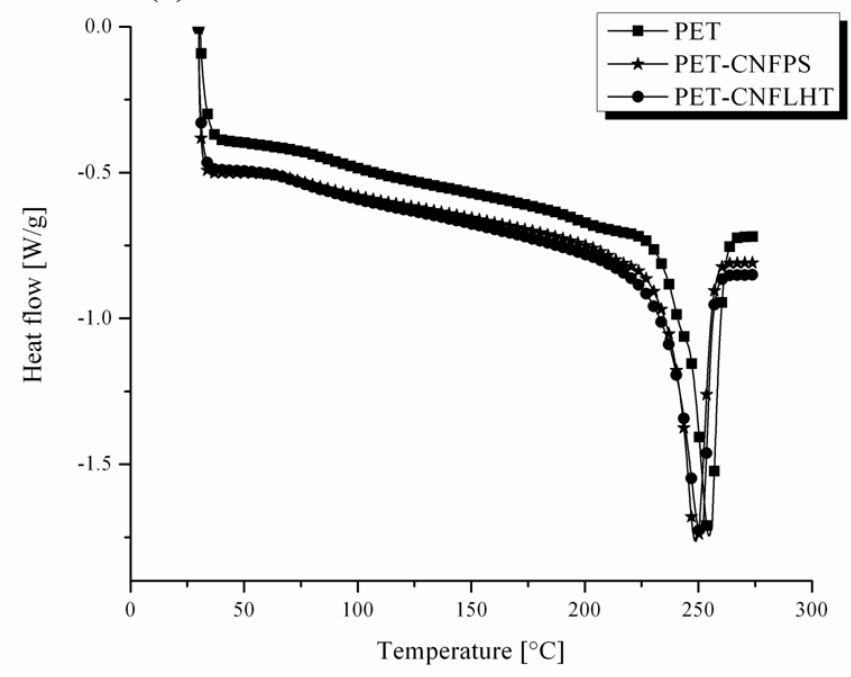

Fig. 5. DSC $2^{\text {nd }}$ (a) and $3^{\text {rd }}$ cycle (b) curves of PET-CNF nanocomposites.

Tab. 3. Combustion data of PET-CNF nanocomposites.

\begin{tabular}{cccccccccc}
\hline Sample & $\mathrm{TTl} \pm \sigma$ & $\Delta$ & $\mathrm{pkHRR} \pm \sigma$ & $\Delta$ & $\mathrm{TSR} \pm \sigma$ & $\Delta$ & $\mathrm{SEA} \pm \sigma$ & $\Delta$ & $\mathrm{LOI}$ \\
{$[\mathrm{s}]$} & {$[\%]$} & {$\left[\mathrm{kW} / \mathrm{m}^{2}\right]$} & {$[\%]$} & {$\left[\mathrm{m}^{2} / \mathrm{m}^{2}\right]$} & {$[\%]$} & {$\left[\mathrm{Kg} / \mathrm{m}^{2}\right]$} & {$[\%]$} & {$[\%]$} \\
\hline PET & $209 \pm 4$ & - & $523 \pm 60$ & - & $2937 \pm 252$ & - & $403 \pm 26$ & - & 21 \\
$\begin{array}{c}\text { PET- } \\
\text { CNFPS }\end{array}$ & $163 \pm 15$ & -22 & $340 \pm 55$ & -35 & $2782 \pm 109$ & -5 & $380 \pm 20$ & -6 & 23 \\
$\begin{array}{c}\text { PET- } \\
\text { CNFLHT }\end{array}$ & $164 \pm 5$ & -22 & $318 \pm 21$ & -39 & $2520 \pm 62$ & -14 & $333 \pm 16$ & -17 & 23 \\
\hline
\end{tabular}

These results confirm the capability of carbon nanofibers to enhance the fire stability of PET. In literature, usually the employ of carbon nanotubes as flame retardant additives has been well documented. Indeed, their highly elongated shape and thus 
the high aspect ratio play a crucial factor in the reduction of the flammability of some polymers such as polypropylene [21, 22], poly methyl methacrylate [23] and poly ethylene vinyl acetate [24]. Analogously, carbon nanofibers can behave similarly to carbon nanotubes as flame retardants promoting the in situ formation of a continuous network structured protective layer from the tubes. This layer acts as physical barrier to oxygen and heat transfer for the polymer leading to a significant reduction in the heat release rate [5].

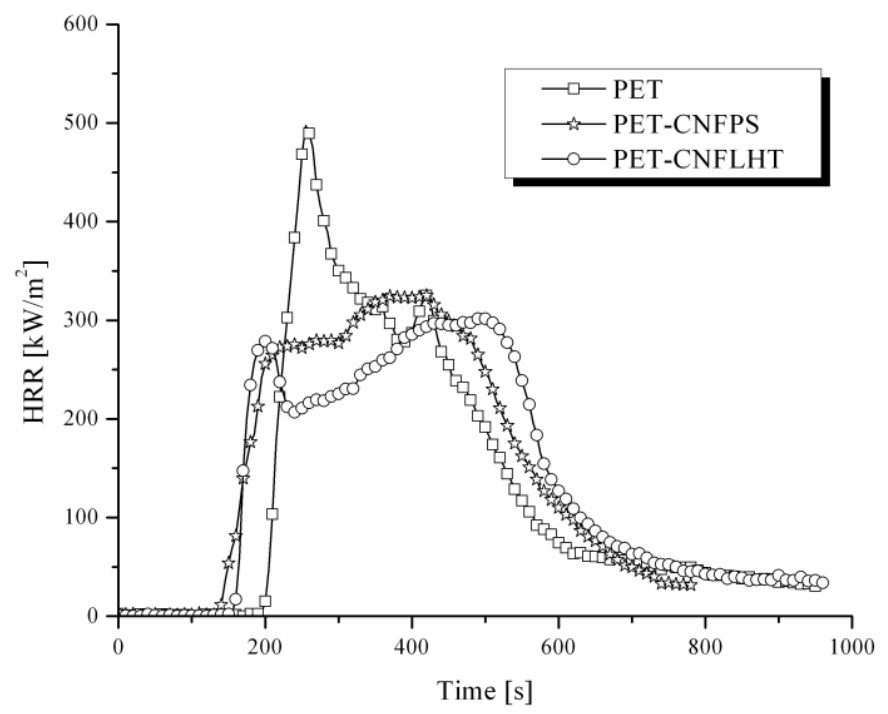

Fig. 6. HRR curves of PET-CNF nanocomposites.

\section{PET-CNF fibers}

The mechanical characteristics of the fibers from CNFPS described in Table 4 show an increase of the elongation at break of $22 \%$ and a decrease of the tensile strength and tenacity of 53 and $35 \%$, respectively if compared to neat PET.

Tab. 4. Mechanical properties of PET fibers.

\begin{tabular}{cccc}
\hline Mechanical properties & PET-CNFPS05 & Reference & $\Delta[\%]$ \\
\hline Elongation at break [\%] & 34.4 & 28.1 & +22 \\
Breaking load [cN] & 452.1 & 691.0 & -34 \\
Tenacity [cN/tex] & 26.1 & 40.0 & -35 \\
\hline
\end{tabular}

The combustion behavior of PET-CNFPS05 textile is compared in Table 5 and Figure 7 with data obtained from the commercial benchmark formulation PET-FR05. TTI decreases for the presence of both fillers: for PET-CNFPS05 the variation is of $-20 \%$, while for PET-FR05 is $-16 \%$. Regarding the HRR, the related peak decreases in a drastic manner in presence of both CNFPS05 and FR05 (45 and 44\%): indeed, the pkHRR decreases from 510 to 282 and $288 \mathrm{~kW} / \mathrm{m}^{2}$ for PET-CNFPS05 and PETFR05, respectively. Regarding TSR, a decrease of 12 and $40 \%$ has been measured for PET-FR05 and PET-CNFPS05, respectively. Unfortunately, the optical density of smoke identified by SEA value increases in presence of CNFs when compared with neat PET. 
Tab. 5. Combustion data of PET fibers.

\begin{tabular}{|c|c|c|c|c|c|c|c|c|c|c|}
\hline Sa & $\begin{array}{c}\mathrm{TTI} \pm \sigma \\
{[\mathrm{s}]}\end{array}$ & $\begin{array}{c}\Delta \\
{[\%]}\end{array}$ & & $\begin{array}{c}\Delta \\
{[\%]}\end{array}$ & [\%] & $\begin{array}{c}\Delta \\
{[\%]}\end{array}$ & & $\begin{array}{c}\Delta \\
{[\%]}\end{array}$ & $\begin{array}{l}\mathrm{SE} \\
{[\mathrm{Kc}}\end{array}$ & $\begin{array}{c}\Delta \\
{[\%]}\end{array}$ \\
\hline & $128 \pm 10$ & 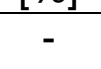 & & 5 & & 2 & & 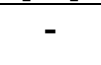 & & - \\
\hline & $108 \pm$ & -16 & $8 \pm$ & & & 7 & & -12 & 65 & $+4 \varepsilon$ \\
\hline & $2 \pm 2$ & -20 & \pm 28 & -45 & $14 \pm 6$ & -18 & $329 \pm 30$ & -40 & $476 \pm 11$ & +34 \\
\hline
\end{tabular}

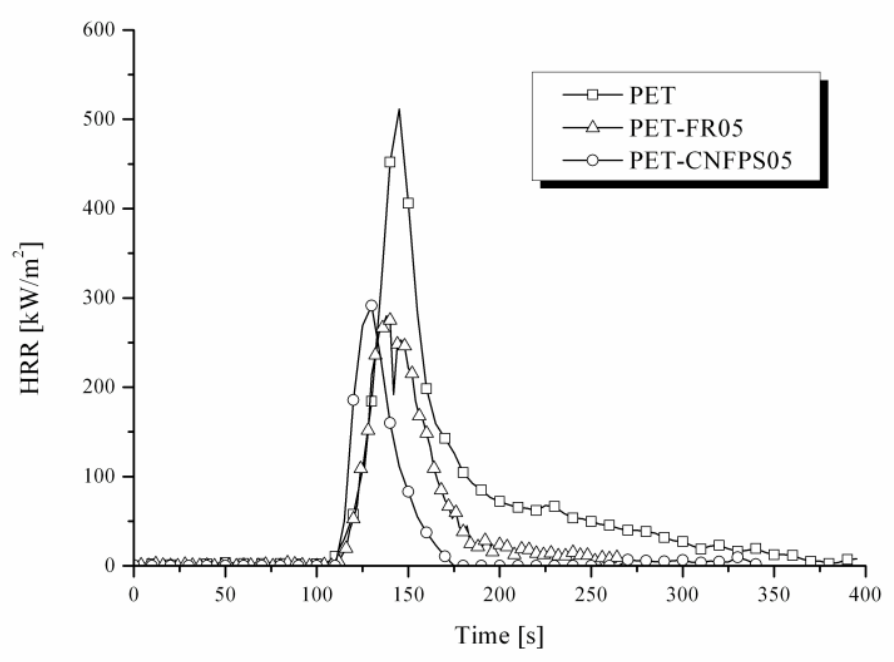

Fig. 7. HRR curves of PET fiber.

\section{Experimental part}

\section{Materials}

Poly(ethylene terephthalate) was provided by Sinterama S.p.A., whereas CNFs were purchased from Pyrograf ${ }^{\circledR}$ Products Inc. Two types of CNFs having different purity grade (of carbonaceous residue amount) were used as received: CNFPS and CNFLHT. Table 6 summarizes their characteristics.

Tab. 6. Structures and codes of the carbon fibers used.

\begin{tabular}{llll}
\hline Trade name & Code & Characteristics & $\begin{array}{l}\text { Nanofiber } \\
\text { grade }\end{array}$ \\
\hline $\begin{array}{l}\text { Pyrograf III PR-24-XT- } \\
\text { PS }\end{array}$ & CNFPS & $\begin{array}{l}\text { Pirolytically stripped carbon } \\
\text { fibers }\end{array}$ & Medium purity \\
\hline $\begin{array}{l}\text { Pyrograf III PR-24-XT- } \\
\text { LHT }\end{array}$ & CNFLHT & Heat treated carbon fibers & High purity \\
\hline
\end{tabular}

Fire retardant commercial PET textile STOPFIRE ${ }^{\circledR}$ supplied by Sinterama S.p.A. was used as a benchmark. The code used within this work is PET-FR05. 


\section{Preparation of PET-CNF nanocomposites}

Melt blending for preparation of 5wt.-\% CNFPS- and CNFLHT- PET masterbatches was carried out using a twin screw extruder (Leistritz ZSE 18 HP 40D) which temperature and screw profile is described in Figure 8 . Before melt blending, materials were dried in a vacuum oven $\left(8 \mathrm{~h}\right.$ at $\left.120^{\circ} \mathrm{C}\right)$.

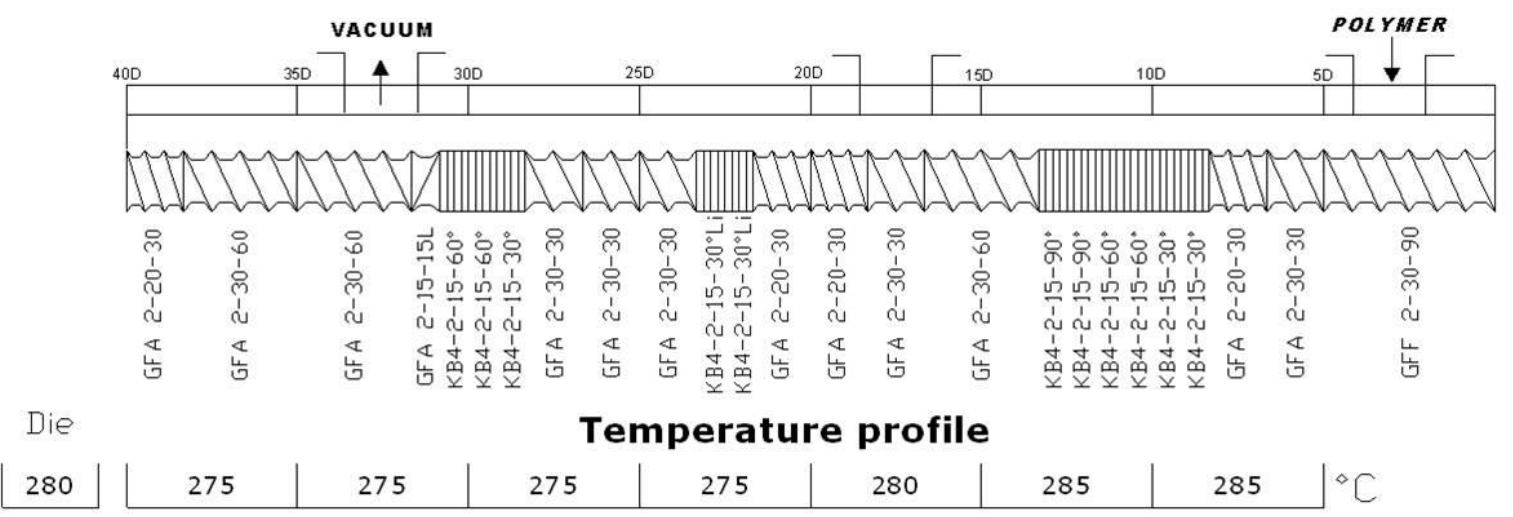

Fig. 8. Temperature and screw profile of the extruder.

\section{Preparation of PET-CNF specimens}

The specimens for cone calorimetry $(100 \times 100 \times 6 \mathrm{~mm})$ and LOI test $(80 \times 6.5 \times 3 \mathrm{~mm})$ were prepared by injection molding.

\section{Spinning of PET-CNF fibers}

Spinning was performed diluting the PET-CNF compound to $0.5 \mathrm{wt} .-\%$ inorganic content at $285^{\circ} \mathrm{C}$ and $3200 \mathrm{~m} / \mathrm{min}$ producing PET-CNF fibers. Filament number of fibers was 48 and the count was 173.48 Dtex. The fibers have been then textured (drawn and bulked) to obtain textile thread (textured yarn) used for the flammability tests. Density of textile fabrics was $152 \mathrm{~g} / \mathrm{m}^{2}$.

\section{Scanning Electron Microscopy (SEM)}

Observations were carried out using a Leica Electron Optics 435 VP SEM with an acceleration voltage of $15 \mathrm{kV}$ and a $20 \mathrm{~mm}$ working distance. Specimens were mounted on aluminum stubs with double sided adhesive tape. The metallization with gold was performed in rarefied argon atmosphere $(20 \mathrm{~Pa})$ using an Emitech K550 Sputter Coater, with a current of $20 \mathrm{~mA}$ for $180 \mathrm{~s}$.

In order to investigate the average diameter of CNFs taken in consideration, a statistical investigation using the software IMAGEJ was performed on a series of 100 fibers selected in SEM micrographs.

\section{Field Emission Scanning Electron (FESEM)}

Examinations were performed with a Zeiss Supra_ 40 on the surface of fragile fracture from samples fractured after cooling by immersion in liquid nitrogen. The samples were coated with chromium. 


\section{ThermoGravimetric Analysis (TGA)}

A TA instruments Q500 thermo-balance provided with a platinum pan was used. The measures are conducted in nitrogen or air atmosphere: $\left(60 \mathrm{~cm}^{3} / \mathrm{min}\right)$ in the range 50 $800^{\circ} \mathrm{C}$ with heating rate of $10{ }^{\circ} \mathrm{C} / \mathrm{min}$. The experimental error was $\pm 0.5 \%$ by weight. The data collected were $T_{\text {onset }}$ ( $5 \%$ of weight loss), $T_{\max }$ (maximum rate of weight loss) and the final residue.

\section{Differential Scanning Calorimetry (DSC)}

Thermal analysis was carried out on a Model QA1000; TA Instrument DSC. Three successive cycles were performed following the scheme:

$1^{\text {st }}$ cycle: heating $25-280^{\circ} \mathrm{C}$ at $20^{\circ} \mathrm{C} / \mathrm{min}$ and isothermal at $280^{\circ} \mathrm{C}$ for $3 \mathrm{~min}$.

$2^{\text {nd }}$ cycle: cooling $280-25^{\circ} \mathrm{C}$ at $10^{\circ} \mathrm{C} / \mathrm{min}$ and isothermal at $25^{\circ} \mathrm{C}$ for $3 \mathrm{~min}$.

$3^{\text {rd }}$ cycle: heating conditions as $1^{\text {st }}$ cycle.

Crystallinity $\left(X_{c}\right)$ value was calculated following equations (1) and (2) [20]:

$\mathrm{X}_{\mathrm{c}}=\Delta \mathrm{H}_{\mathrm{c}}{ }^{*} 100 / \Delta \mathrm{H}_{\mathrm{m}}{ }^{0}=\Delta \mathrm{H}_{\mathrm{c}}{ }^{*} 100 / 140$ for PET

$\mathrm{X}_{\mathrm{c}}=\Delta \mathrm{H}_{\mathrm{c}}{ }^{*} 100 / \Delta \mathrm{H}_{\mathrm{m}}{ }^{0}(1-\Phi)=\Delta \mathrm{H}_{\mathrm{c}}{ }^{*} 100 / \Delta \mathrm{H}_{\mathrm{m}}{ }^{0}(1-0.05)$, for PET-CNF nanocomposites

\section{Oxygen consumption calorimetry (Cone calorimeter test)}

A cone calorimeter (Fire Testing Technology, FTT) was used under a heat flux of 35 $\mathrm{kW} / \mathrm{m}^{2}$ according to ISO $5660-1$. The parameters measured were time to ignition (TTI, s), heat release rate $\left(\mathrm{HRR}, \mathrm{kW} / \mathrm{m}^{2}\right.$ ) and the relative peak (pkHRR, $\mathrm{kW} / \mathrm{m}^{2}$ ), total heat release $\left(T H R, \mathrm{~kW} / \mathrm{m}^{2}\right)$, residue $(\%)$, total smoke release $\left(\mathrm{TSR}, \mathrm{m}^{2} / \mathrm{m}^{2}\right.$ ) and specific extinction area $\left(\mathrm{SEA}, \mathrm{Kg} / \mathrm{m}^{2}\right)$. For each formulation, the test was repeated three times and standard deviation $(\sigma)$ was reported for each measurement.

\section{Limiting oxygen index (LOI)}

LOI value was measured by oxygen index apparatus (FIRE) according to the ISO 4589-2 standard.

\section{Mechanical test on fibers}

The mechanical properties were measured directly on spun fibers using a Textechno, Statimat II model dynamometer according to the EN ISO 2062 standard.

\section{Acknowledgements}

The authors would like to thank Dr. Nils Wenne for the discussion, and Ing. Emanuele Pivotto for the support, as well as FLEXIFUNBAR project $2004 / 2008$ for funding $\left(6^{\text {th }}\right.$ Framework Program, contractual $n^{\circ}$ 505864). Furthermore, the authors would like to thank Prof. Giovanni Camino for the fruitful discussion and the support.

\section{References}

[1] Pinnavaia, T.J.; Beall, G.W. editors. Polymer-clay nanocomposites, John Wiley \& Sons; 2001 New York.

[2] Utracki, L.A.; Sepehr, M.; Boccaleri, E. Polym. Adv. Technol. 2007,18, 1.

[3] Ray, S.S.; Okamoto, M. Prog. Polym. Sci. 2003, 28, 1539 and references quoted therein.

[4] Alexandre, M.; Dubois, P. Mater. Sci. Technol. R 2000, 28, 1. 
[5] Gilman, J.W.; Kashiwagi, T. SAMPE J 1997, 33, 40.

[6] Gilman, J.W. Appl. Clay Sci. 1999, 15, 31.

[7] Gilman, J.W.; Jackson, C.L.; Morgan, A.B.; Harris, R.H.; Manias, E.; Giannelis, E.P.; Wuthenow, M.; Hilton, D.; Phillips, S.H. Chem. Mater. 2000,12, 1866.

[8] Zanetti, M.; Camino, G.; Müllhaupt, R. Polym. Degrad. Stab. 2001, 74, 413.

[9] Zhu, J.; Uhl, F.M.; Morgan, A.B.; Wilkie, C.A. Chem. Mater. 2001, 13, 4649.

[10] Alexandre, M.; Beyer, G.; Henrist, C.; Cloots, R.; Rulmont, A.; Jerome, R.; Dubois, P. Macromol. Rapid Commun. 2001, 22, 943.

[11] Zhu, J.; Start, P.; Mauritz, A.; Wilkie, C.A. Polym. Degrad. Stab. 2002, 77, 253.

[12] Morgan, A.B.; Harris, R.H.; Kashiwagi, T.; Chyall, L.J.; Gilman, J.W. Fire Mater 2002, 26, 247.

[13] Kashiwagi, T.; Harris, R.H.; Zhang, X.; Briber, R.M.; Cipriano, B.H.; Raghavan, S.R.; Awad, W.H.; Shields, J.R. Polymer 2004, 45, 881.

[14] Kashiwagi, T.; Grulke, E.; Hilding, J.; Groth, K.; Harris, R.H.; Butler, K.; Shields, J.; Kharchenko T.; Douglas, J. Polymer 2004, 45, 4227.

[15] Kashiwagi, T.; Du, F.; Winey, K.I.; Groth, K.M.; Shields, J.R.; Bellayer, S.P.; Kim, H.; Douglas, J.F. Polymer 2005, 46, 471.

[16] Kashiwagi, T.; Fagan, J.; Douglas, J.F.; Yamamoto, K.; Heckert, A.N.; Leigh, S.D.; Obrzut, J.; Du, F.; Gibson, S.L.; Mu, M.; Winey, K.I.; Haggenmueller, R. Polymer 2007, 48, 4855.

[17] Bocchini, S.; Frache, A.; Camino, G.; Claes, M. Eur Polym J. 2007, 43, 3222.

[18] Bocchini, S.; Annibale, E.; Frache, A.; Camino, G. e-polymer 2008, no. 20.

[19] Ma, H.; Zeng, J.; Realff, M.L.; Kumar, S.; Schiraldi, D.A. Compos. Sci. Technol. 2003, 63, 1617.

[20] Tjong, S.C.; Bao, S.P. J. Polym. Sci. Part B: Polym. Phys. 2004, 42, 2878.

[21] Kashiwagi, T.; Harris, R.H.; Zhang, X.; Briber, R.M.; Cipriano, B.H.; Raghavan, S.R.; Awad, W.H.; Shields, J.R. Polymer 2004, 45, 881.

[22] Kashiwagi, T.; Grulke, E.; Hilding, J.; Harris, R.; Awad, W.H; Douglas, J.F. Macromol Rapid Commun 2002, 23, 761.

[23] Kashiwagi, T.; Du, F.; Winey, K.I.; Groth, K.M.; Shields, J.R.; Bellayer, S.P.; Kim, H.; Douglas, J.F. Polymer 2005, 46, 471.

[24] Kashiwagi, T.; Grulke, E.; Hilding, J.; Groth, K.M.; Harris, R.; Butler, K.; Shields, J.R; Kharchenko, S.; Douglas, J. Polymer 2004, 45, 4227. 